\title{
KARAKTERISTIK DAN PENGOBATAN PASIEN STROKE DIINSTALASI RAWAT INAP RSUD A.W. SJAHRANIE SAMARINDA PERIODE 2014
}

\author{
Claudea Ersamy Janafrish*, Adam M. Ramadhan, Laode Rijai \\ Laboratorium Penelitian dan Pengembangan Kefarmasian "Farmaka Tropis", \\ Fakultas Farmasi, Universitas Mulawarman, Samarinda \\ *Email : claudeaersamy@yahoo.com
}

\begin{abstract}
The research with title "Characteristics and Treatment of Stroke Patients Installed Inpatient in A. W. Sjahranie Samarinda Hospital Period 2014" has been conducted. This study aims to determine characteristics of stroke patients, characteristics of stroke in patients, and treatment in stroke patients as well as drug interactions. Results of the study patient characteristics include sex highest percentage of males 71 patients (54\%), highest percentage of patients who suffered strokes in patients aged $>44$ years by 114 patients (86\%) and type of work highest percentage of employees private as 96 patients (73\%). Results of the characteristics of stroke by stroke type frequency at highest percentage of ischemic stroke 75 patients (57\%), frequency of the patient's level of consciousness 87 patients (66\%) on GCS 15. Treatment is based on selection of classes and types of drugs most commonly used are ones activator and cerebral vasodilator types citicolin, nootropik and neurotrophic types Piracetam and antiplatelet drug types Clopidogrel. Administered dose is different, this is adjusted several factors such as condition of patient, patient's age and diagnosis. Most administration route of drugs intravenously. Drug interactions that occur in form of pharmacodynamic interaction between Clopidogrel with Simvastatin, Clopidogrel with Aspilet, Aspilet with Captopril, and Aspilet with Furosemide.
\end{abstract}

Keywords: Stroke, Characteristics, Treatment, Hospital. A. W. Sjahranie Samarinda

\begin{abstract}
Abstrak
Telah dilakukan penelitian dengan judul "Karakteristik dan Pengobatan Pada Pasien Stroke Di Instalasi Rawat Inap di RSUD A.W. Sjahranie Samarinda Periode 2014". Penelitian ini bertujuan untuk mengetahui karakteristik pasien stroke, mengetahui karakteristik stroke pada pasien, dan mengetahui pengobatan pada
\end{abstract}


pasien stroke serta interaksi obat. Hasil penelitian karakteristik pasien yang meliputi jenis kelamin persentase tertinggi laki-laki sebesar 71 pasien (54\%), hasil persentase tertinggi pasien stroke yang diderita pada pasien usia $>44$ tahun sebesar 114 pasien $(86 \%)$ dan jenis pekerjaan persentase tertinggi adalah pegawai swasta sebanyak 96 pasien (73\%). Sedangkan hasil karakteristik stroke berdasarkan frekuensi jenis stroke persentase tertinggi pada stroke iskemik sebesar 75 pasien (57\%), frekuensi tingkat kesadaran pasien sebesar 87 pasien (66\%) pada GCS 15. Pengobatan berdasarkan pemilihan golongan dan jenis obat yang paling sering digunakan adalah golongan aktivator serebral dan vasodilator dengan jenis obat citicolin, nootropik dan neurotropik dengan jenis obat Piracetam dan antiplatelet dengan jenis obat Clopidogrel. Dosis obat yang diberikan berbeda-beda, hal ini disesuaikan dengan beberapa faktor dari pasien misalnya kondisi pasien, umur dan diagnosis pasien. Sedangkan rute pemberian obat yang terbanyak diberikan secara intravena. Interaksi obat yang terjadi berupa interaksi farmakodinamik antara Clopidogrel dengan Simvastatin, Clopidogrel dengan Aspilet, Aspilet dengan Captopril dan Aspilet dengan Furosemid.

Kata Kunci: Stroke, Karakteristik, Pengobatan, RSUD. A. W. Sjahranie Samarinda

\section{PENDAHULUAN}

Sistem saraf adalah jaringan komunikasi utama di dalam tubuh manusia. Seperti pada vertebrata lainnya, fungsi normal sistem saraf sangat bergantung pada terpeliharanya integritas struktural, serta sejumlah proses metabolik kompleks. Oleh karena itu, proses yang mengganggu struktur atau metabolisme normal, atau keduanya dapat menimbulkan penyakit neurologik. Gangguan pada sistem saraf sering dianggap lebih rumit atau misterius dibandingkan dengan sistem organ lain $[5]$.

Menurut WHO, stroke adalah adanya tanda-tanda klinik yang berkembang cepat akibat gangguan fungsi otak fokal (atau global) dengan gejala-gejala yang berlangsung selama 24 jam atau lebih yang menyebabkan kematian tanpa adanya penyebab lain yang jelas selain vaskular. Stroke adalah kehilangan fungsi otak yang diakibatkan oleh berhentinya suplai darah ke bagian otak [4].

Stroke adalah sindrom yang disebabkan oleh gangguan peredaran darah otak (GDPO) dengan awitan akut, disertai manifestasi klinis berupa defisit neurologis dan bukan sebagai akibat trauma ataupun infeksi. Stroke merupakan penyebab kecacatan nomor satu di dunia dan penyebab kematian nomor tiga di dunia. Duapertiga stroke terjadi di negara berkembang. Pada masyarakat barat, $80 \%$ penderita mengalami stroke iskemik dan 20\% mengalami stroke hemoragik. Insiden stroke meningkat seiring pertambahan usia [2].

Di Indonesia jumlah penderita stroke dari tahun ke tahun terus meningkat. Ini sejalan dengan perubahan pola hidup masyarakat. Hingga kini, stroke merupakan penyebab kematian nomor satu di berbagai rumah sakit di tanah air. Survei kesehatan rumah tangga menunjukkan bahwa stroke merupakan penyebab kematian/kecacatan utama di Indonesia [3]. 
Masalah stroke di Indonesia menjadi semakin penting dan mendesak, karena kini jumlah penderita stroke di Indonesia terbanyak di Asia. Jumlah penderita stroke dengan rata-rata berusia 60 tahun ke atas berada di urutan kedua terbanyak di Asia, sedangkan usia 15-59 tahun berada di urutan ke lima terbanyak di Asia. Jumlah penderita stroke mencapai 8,3 per 100 populasi di Indonesia dengan populasi sekitar 211 juta jiwa, berarti terdapat sekitar 1,7 juta penderita stroke di Indonesia [1].

\section{METODE PENELITIAN}

Penelitian ini dilakukan secara deskriptif dengan pengambilan data cara retrospektif. Metode yang digunakan adalah teknik systematic sampling. Jumlah keseluruhan sampel 132 pasien dengan kriteria inklusi sebanyak 118 pasien, yaitu pasien dengan diagnosa terakhir stroke serta mempunyai data rekam medik yang lengkap.

Proses pengambilan data pada penelitian ini dimulai dari dilakukannya umum rekam medik pasien stroke sepanjang tahun 2014. Kemudian ditetapkan jumlah sampel yang ingin diteliti, selanjutnya dilakukan pencatatan atau pengumpulan data. Setelah itu, data di analisis dan dibuat tabulasi data. Dari hasil analisis data tersebut dapat ditentukan karakteristik pasien yang meliputi jenis kelamin, usia, jenis pekerjaan, karakteristik stroke pada pasien yang meliputi frekuensi jenis stroke, frekuensi tingkat kesadaran pasien berdasarkan nilai GCS (Glasgow Coma Scale) dan mengetahui pengobatan pada pasien stroke yang meliputi pemilihan jenis dan golongan, obat, penetapan dosis, rute pemberian, dan interaksi obat.

\section{HASIL DAN PEMBAHASAN}

Karakteristik Pasien

Gambaran Penderita Berdasarkan Jenis Kelamin
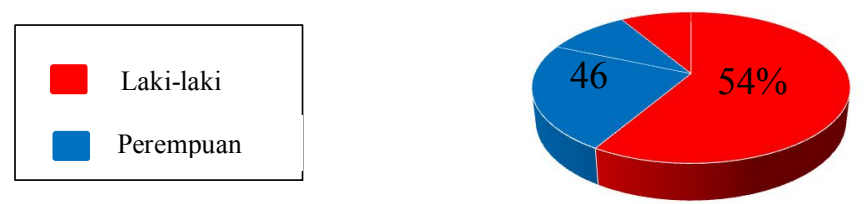

Gambar 1. Diagram Distribusi Jenis Kelamin Pasien Stroke di Instalasi Rawat Inap RSUD A. W. Sjahranie Samarinda Periode Tahun 2014 
Diagram diatas menunjukkan bahwa sebanyak 71 pasien (54\%) laki-laki, sedangkan sebanyak 61 pasien (46\%) perempuan. Pada penelitian ini dapat terlihat bahwa kejadian stroke lebih banyak dialami oleh laki-laki dibandingkan perempuan. Hal tersebut disebabkan karena perempuan memiliki lebih banyak hormon esterogen dibandingkan laki-laki. Namun, setelah mengalami proses menopouse, risiko perempuan untuk mengalami stroke sama dengan laki-laki. Selain itu, laki-laki lebih berisiko mengalami stroke karena memiliki beberapa faktor risiko seperti merokok, mengkonsumsi alkohol dan lain-lain.

\section{Gambaran Penderita Berdasarkan Usia}
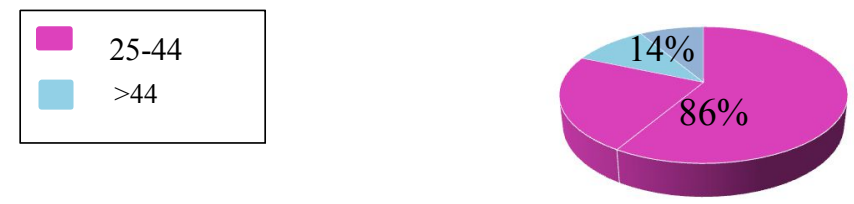

Gambar 2. Diagram Distribusi Usia Pasien Stroke di Instalasi Rawat Inap RSUD A. W. Sjahranie Samarinda Periode Tahun 2014

Hasil penelitian pada gambar $2 \mathrm{di}$ atas diperoleh persentase pasien stroke pada usia 25-44 tahun berjumlah 18 pasien (14\%), sedangkan pasien stroke pada usia di atas 44 tahun berjumlah 114 pasien $(86 \%)$. Hal tersebut memberikan gambaran bahwa pola penyakit stroke pertama kali cenderung terjadi pada golongan umur yang lebih tua tapi masih produktif. Dengan demikian, seiring pertambahan usia risiko stroke iskemik dan perdarahan intraserebral meningkat menjadi dua kali lipat setiap tahunnya pada usia 44 tahun ke atas.

\section{Gambaran Penderita Berdasarkan Jenis Pekerjaan}

Swasta

PNS

IRT

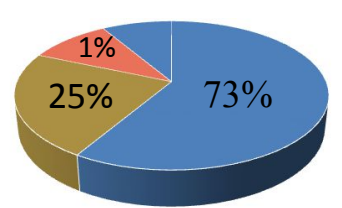

Gambar 3. Diagram Distribusi Jenis Pekerjaan Pasien Stroke di Instalasi Rawat Inap RSUD A. W. Sjahranie Samarinda Periode Tahun 2014

Hasil penelitian pada gambar 3 di atas diperoleh persentase pasien yang bekerja sebagai PNS sebanyak 34 pasien (25\%), swasta sebanyak 96 pasien (73\%) dan IRT sebanyak 2 pasien (1\%) dari jumlah pasien keseluruhan. Hal tersebut 
kemungkinan disebabkan oleh stres psikologis akibat pekerjaan yang dapat meningkatkan risiko stroke. Risiko stroke akibat stress kerja lebih besar 1,4 kali pada pria dari kalangan ekonomi menengah keatas.

\section{Karakteristik Stroke}

\section{Gambaran Penderita Berdasarkan Frekuensi Jenis Stroke}
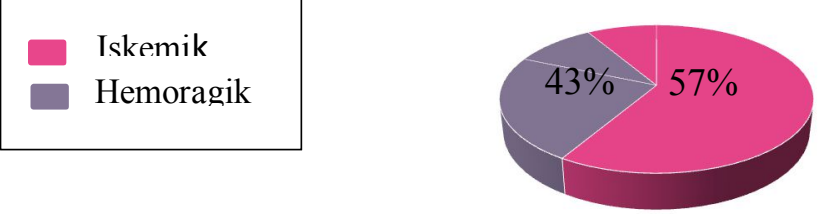

Gambar 4. Diagram Distribusi Frekuensi Jenis Stroke pada Pasien Stroke di Instalasi Rawat Inap RSUD A. W. Sjahranie Samarinda Periode Tahun 2014

Dari jumlah keseluruhan pasien stroke, diperoleh sebanyak 75 pasien (57\%) mengalami stroke iskemik dan sebanyak 57 pasien (43\%) mengalami stroke hemoragik. Hal tersebut menunjukkan bahwa insidensi stroke iskemik lebih sering terjadi dibandingkan dengan stroke hemoragik.

\section{Gambaran Tingkat Kesadaran Pasien Berdasarkan Nilai GCS}

Glasgow coma scale (GCS) merupakan instrumen standar yang dapat digunakan untuk mengukur tingkat kesadaran pasien trauma kepala.
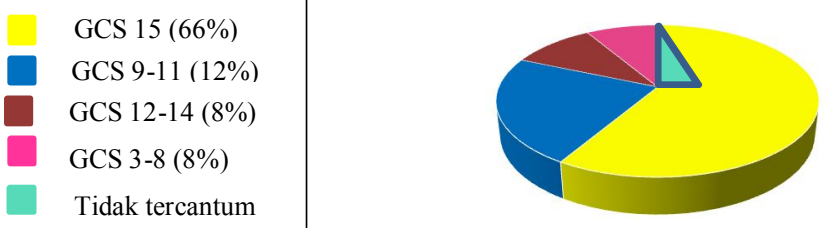

Gambar 5. Diagram Distribusi Frekuensi Tingkat Kesadaran Berdasarkan Nilai GCS pada Pasien Stroke di Instalasi Rawat Inap RSUD A. W. Sjahranie Samarinda Periode Tahun 2014.

Keterangan:

GCS 15

GCS 12-14

: compos mentis (kesadaran baik/normal)

GCS 9-11

: somnolen (agak menurun/apatis)

GCS 3-8

: sopor (seperti mengantuk)

Tidak tercantum

coma (tidak sadar)

: tidak tertera GCS pasien 
Hasil penelitian ini diperoleh jumlah pasien dengan GCS 15 sebanyak 87 pasien (66\%), jumlah pasien dengan GCS 12-14 sebanyak 10 pasien (8\%), jumlah pasien dengan GCS 9-11 sebanyak 16 pasien (12\%), jumlah pasien dengan GCS 38 sebanyak 11 pasien (8\%), dan jumlah pasien yang tidak tercantum nilai GCSnya sebanyak 8 pasien $(6 \%)$. Dari hasil tersebut, dapat diketahui bahwa tingkat kesadaran pasien stroke diinstalasi rawat inap RSUD A. W. Sjahranie Samarinda sebagian besar termasuk ke dalam kategori yang normal (kesadaran baik) dan hanya sebagian kecil tingkat kesadaran pasien yang mengalami koma. Hal ini dapat tergantung pada seberapa luasnya infark atau pendarahan yang dialami pasien sehingga dapat mempengaruhi kesadaran pasien tersebut.

\section{Pengobatan pada Pasien Stroke}

\section{Pemilihan dan Jenis Obat yang Diberikan}

Tabel 1. Profil Penggunaan Obat Pada Pasien Stroke di Instalasi Rawat Inap RSUD A. W. Sjahranie Samarinda periode 2014

\begin{tabular}{|c|c|c|c|c|c|c|c|}
\hline \multirow[b]{2}{*}{ No. } & \multirow[b]{2}{*}{$\begin{array}{c}\text { Golongan } \\
\text { Obat }\end{array}$} & \multicolumn{2}{|c|}{ Jenis Stroke } & \multicolumn{4}{|c|}{ Nama Obat } \\
\hline & & SNH & $\mathrm{SH}$ & Generik & $\begin{array}{c}\text { Jumlah } \\
(\%)\end{array}$ & Paten & $\begin{array}{c}\text { Jumlah } \\
(\%)\end{array}$ \\
\hline 1. & $\begin{array}{l}\text { Aktivator } \\
\text { serebral dan } \\
\text { vasodilator }\end{array}$ & $\sqrt{ }$ & $\sqrt{ }$ & Citicolin & $50 \%$ & Brainact & $36 \%$ \\
\hline \multirow[t]{5}{*}{2.} & $\begin{array}{l}\text { Nootropik } \\
\text { dan }\end{array}$ & $\sqrt{ }$ & $\sqrt{ }$ & Piracetam & $16 \%$ & & \\
\hline & neurotropik & $\sqrt{ }$ & & & & Neurotam & $13 \%$ \\
\hline & & & $\sqrt{ }$ & & & Meticobal & $1 \%$ \\
\hline & & $\sqrt{ }$ & & & & Lanabal & $1 \%$ \\
\hline & & $\sqrt{ }$ & $\sqrt{ }$ & & & Kalmeco & $7 \%$ \\
\hline \multirow[t]{4}{*}{3.} & Antiplatelet & $\sqrt{ }$ & & & & Plavix & $2 \%$ \\
\hline & & $\sqrt{ }$ & & & & Plasmin & $2 \%$ \\
\hline & & $\sqrt{ }$ & $\sqrt{ }$ & & & Aspilet & $22 \%$ \\
\hline & & $\sqrt{ }$ & & & & CPG & $33 \%$ \\
\hline
\end{tabular}

Keterangan: $\mathrm{SH} \quad$ : Stroke Hemoragik

SNH : Stroke Non-hemoragik 


\begin{tabular}{lllll}
\hline $\begin{array}{lll}\text { Aktivator serebral dan } \\
\text { vasodilator perifer }\end{array}$ & Citicolin & & $\sqrt{ }$ & $50 \%$ \\
Nootropik dan & Brainact & & $\sqrt{ }$ & $36 \%$ \\
neurotropik & Piracetam & $\sqrt{ }$ & & $16 \%$ \\
& Neurotam & & $\sqrt{ }$ & $13 \%$ \\
& Meticobal & & $\sqrt{ }$ & $1 \%$ \\
& Lanabal & $\sqrt{ }$ & & $1 \%$ \\
Kalmeco & & $\sqrt{ }$ & $7 \%$ \\
& Klasmin & $\sqrt{ }$ & & $2 \%$ \\
& Aspilet & $\sqrt{ }$ & & $22 \%$ \\
& Clopidogrel & $\sqrt{ }$ & & $39 \%$ \\
& Plavix & $\sqrt{ }$ & & $2 \%$ \\
\hline
\end{tabular}

Berdasarkan tabel 3, diperoleh persentase rute pemberian obat pada pasien stroke sebagian besar diberikan secara intravena. Tujuan dari rute pemberian obat secara intravena yaitu untuk memberikan suatu efek yang cepat dan kontrol yang baik sekali atas kadar obat dalam sirkulasi. Dengan pemberian IV, obat menghindari saluran cerna dan oleh karena itu menghindari metabolisme first pass oleh hati sehingga langsung masuk ke dalam pembuluh darah dan memberikan efek yang cepat.

\section{Interaksi Obat}

Berdasarkan hasil kajian dari literatur, diperoleh potensi interaksi obat yang dapat terjadi pada pasien stroke yang dapat dilihat pada tabel 4.

Tabel 4. Distribusi Potensi Interaksi Obat pada Pasien Stroke di Instalasi Rawat Inap RSUD A. W. Sjahranie Samarinda

\begin{tabular}{lll}
\multicolumn{1}{c}{$\begin{array}{c}\text { Jenis Obat } \\
\text { (I) }\end{array}$} & \multicolumn{1}{c}{$\begin{array}{c}\text { Jenis Obat } \\
\text { (II) }\end{array}$} & \multicolumn{1}{c}{$\begin{array}{c}\text { Jenis Interaksi } \\
\text { Obat }\end{array}$} \\
\hline Clopidogrel & Simvastatin & Farmakodinamik \\
Aspilet & Clopidogrel & Farmakodinamik \\
Aspilet & Captopril & Farmakodinamik \\
Aspilet & Furosemid & Farmakodinamik \\
\hline
\end{tabular}

Dari tabel 4, menunjukkan bahwa terjadi beberapa interaksi farmakodinamik antara obat dengan obat. Interaksi yang terjadi pada kombinasi obat antara Clopidogrel dan simvastatin ditemukan dapat menghambat aktivasi Clopidogrel sebagai antiplatelet sehingga dapat menurunkan efek terapi dari clopidogrel. Sedangkan interaksi yang terjadi pada penggunaan clopidogrel dengan aspilet secara bersamaan, dapat meningkatkan risiko pendarahan apabila diberikan pada dosis tinggi (dosis aspirin $>100 \mathrm{mg} /$ hari). Akan tetapi, apabila penggunaan 
diberikan pada dosis rendah secara bersamaan dapat meningkatkan efek terapi sebagai antiplatelet. Aspilet dengan captopril bila digunakan secara bersamaan dapat mengurangi efek antihipertensi dari captopril, namun dapat meningkat hanya pada dosis tinggi $(300 \mathrm{mg})$. Penggunaan aspilet bersama furosemid dapat menurunkan efek dari furosemid.

\section{KESIMPULAN}

Berdasarkan hasil penelitian karakteristik dan pengobatan pada pasien stroke di instalasi rawat inap di RSUD A. W. Sjahranie Samarinda, maka dapat disimpulkan sebagai berikut :

a. Karakteristik pasien stroke berdasarkan jenis kelamin yang paling banyak yaitu laki-laki sebanyak 71 pasien dengan persentase $54 \%$. Berdasarkan usia yang paling banyak yaitu dengan usia $>44$ tahun sebanyak 114 pasien dengan persentase $86 \%$. Berdasarkan jenis pekerjaan yang paling banyak yaitu efek

b. Karakteristik stroke berdasarkan frekuensi jenis stroke yang paling banyak yaitu stroke iskemik sebanyak 75 pasien dengan persentase $57 \%$. Berdasarkan frekuensi tingkat kesadaran pasien berdasarkan GCS sebesar 87 pasien dengan persentase $66 \%$ pada GCS 15 .

c. Pengobatan berdasarkan pemilihan golongan dan jenis obat yang paling sering digunakan adalah golongan aktivator serebral dan vasodilator, nootropik dan neurotropik. Dosis obat yang diberikan berbeda-beda, karena hal ini disesuaikan dengan beberapa faktor dari pasien misalnya kondisi pasien, umur dan diagnosis pasien. Rute pemberian obat yang terbanyak diberikan secara intravena.

d. Interaksi obat yang terjadi berupa potensi interaksi antara clopidogrel dengan simvastatin, clopidogrel dengan aspilet, aspilet dengan captopril, dan aspilet dengan furosemid berdasarkan teori dan bukti klinis pada literatur.

\section{DAFTAR PUSTAKA}

[1] Burhanuddin M, dkk. 2013. Faktor Risiko Kejadian Stroke Pada Dewasa Awal (18-40 Tahun) Di Kota Makassar Tahun 2010-2012. Fakultas Kesehatan Masyarakat UNHAS. Makassar.

[2] Dewanto G, dkk. 2007. Panduan Praktis Diagnosis dan Tatalaksana Penyakit Saraf. Penerbit Buku Kedokteran EGC. Jakarta.

[3] Irdawati. 2012. Latihan Gerak Terhadap Keseimbangan Pasien Stroke NonHemoragik. Jurnal Kesehatan Masyarakat Volume 2 Nomor 7.

[4] Mutaqqin, A. 2008. Buku Ajar Asuhan Keperawatan Klien Dengan Gangguan Sistem Persarafan. Penerbit Salemba Medika. Jakarta.

[5] Robbins, dkk. 2013. Buku Ajar Patologi Robbins Edisi 7 Volume 2. Penerbit Buku Kedokteran EGC. Jakarta. 